\title{
Low-Dose Metronomic Chemotherapy: Myth or Truth?
}

\author{
Sylvain Baruchel Diana Stempak
}

New Agent and Innovative Therapy Program, Division of Hematology/Oncology, Department of Pediatrics, Hospital for Sick Children, Toronto, Ontario, Canada

Cytotoxic anti-proliferative agents are the mainstay of therapy for pediatric and adult cancer. Based on pre-clinical experiments, the log-dose survival curve model for cancer cell kill became the leading model for chemotherapy dose calculation. Conventional cytotoxic drugs were designed for use at maximum tolerated dose (MTD) to treat cancer [1]. This strategy of MTD chemotherapy has lead to cure and disease control in a significant number of patients but is associated with significant short-term and long-term complications especially in children. Despite an initially impressive tumor regression or even remission, regrowth or recurrence is quite common in metastatic cancer or in tumors of poor biology [2]. Based on this, it is not surprising that pediatric oncologists have a vested interested in minimizing toxicity while increasing drug efficacy.

Recent studies have shown that cytotoxic drugs used at much lower doses and given more frequently (low-dose metronomic (LDM) chemotherapy) may have the potential for anti-cancer efficacy by way of a secondary alternative mechanism, i.e., inhibition of tumor angiogenesis [3-5]. Interestingly, when one looks back at the history of pediatric cancer therapy, several successful approaches could well be called 'metronomic chemotherapy' but instead are known as 'maintenance therapy'. Pediatric oncologists have shown that daily mercaptopurine and weekly methotrexate is a successful combination in leukemia [6]. Further, the combination of weekly vincristine and low-dose daily cyclophosphamide is effective in neuroblastoma [7] and weekly vincristine is often used in Wilms' tumor [8].

Two landmark publications by Klement et al. [9] and Browder et al. [10] demonstrated that LDM chemotherapy has an antiangiogenic effect. Since then a significant number of preclinical studies confirmed the anti-angiogenic effect of LDM chemotherapy, demonstrated increased efficacy when combined with anti-angiogenic agents [11-14], and identified potential surrogate markers of anti-angiogenic activity [15-17].
In this edition of ONKOLOGIE, Sterba and colleagues [18] demonstrate the activity of combining a biodifferentiating agent (retinoic acid) with an 'anti-angiogenic metronomic chemotherapy regimen' (temozolomide, etoposide and celecoxib) and confirm the safety of this approach. Interestingly, they report a very significant $64 \%$ response rate in this heavily pretreated patient population with relapsed or very high-risk diseases. However, it is difficult to conclude whether this combination is truly anti-angiogenic or biodifferentiating or both. The major drawback of their study is the lack of biomarkers to support the mechanism of action of this apparently effective regimen. This study is similar to a recent report from Kieran et al. [19] who demonstrated that the combination of celecoxib, thalidomide, LDM etoposide and LDM cyclophosphamide is safe and can induce long-term stable disease in very heavily pretreated pediatric patients. In this report Kieran also was unable to validate any biomarkers to support the anti-angiogenic nature of this therapy although the attempt to look at changes in the plasma levels of various proteins involved in angiogenesis was made. Our own experience has shown that a 'lower' dose of temozolomide administered regularly or metronomically to a refractory brain tumor patient population can lead to a significant response rate and stable disease. However, this approach can be associated with chronic toxicity such as severe lymphopenia with opportunistic infection and therefore careful patient monitoring is critical [20]. In another of our studies using LDM vinblastine or cyclophosphamide and celecoxib in heavily pretreated patients, we observed impressive durable stable disease with no toxicity [21]. It is important at this time to distinguish between true LDM chemotherapy and a 'lower' dose dense chemotherapy and raise the question of designing rational dosing regimens rather than empirically selecting $10-33 \%$ of the MTD which is often done [22]. In both LDM and dose dense regimens, a shortened interval between doses and lack of an extended rest peri-

\begin{tabular}{ll}
\hline KARGER & @ 2006 S. Karger GmbH, Freiburg \\
Fax +497614520714 & Accessible online at: \\
$\begin{array}{l}\text { E-mail Information@Karger.de } \\
\text { www.karger.com }\end{array}$ & www.karger.com/onk
\end{tabular}

Sylvain Baruchel, M.D.

New Agent and Innovative Therapy Program

Division of Hematology/Oncology

Department of Pediatrics, Hospital for Sick Children, Toronto, Ontario, Canada

Tel. +1 416 813-5977, Fax -5327

E-mail sylvain.baruchel@sickkids.ca 
od between cycles is used; hence they can both be considered 'metronomic'. However, while dose dense chemotherapy involves the administration of doses lower than the MTD, the total cumulative dose for a given cycle is greater than what would have been administered in a classical MTD regimen [19]. The target of dose dense therapy remains to be the tumor cell while in LDM chemotherapy regimens, tumor vasculature is postulated to be the target and this is thought to result in an overall anti-tumor effect. Another important distinction is the toxicity of these two types of regimens. While in both cases, the smaller individual doses result in greater tolerability, toxicity is more common and expected in dose dense regimens. On the other hand, in LDM chemotherapy regimens toxicity is either greatly reduced or absent altogether [23, 24]. This issue of toxicity is illustrated in the two examples from our experience cited above.

In similar metronomic chemotherapy studies in adults, the preliminary results are promising, however, more research with larger sample sizes is required to truly establish the efficacy of these investigational therapies. Recently Buckstein et al. confirmed the efficacy of LDM cyclophosphamide and celecoxib in refractory high-grade lymphoma [25] and Young et al. demonstrated that the combination of low-dose cyclophosphamide, weekly vinblastine and rofecoxib is effective in a subset of Hodgkin's disease patients [26]. Garcia and colleagues have recently reported remarkable findings in their interim analysis of a phase II study of low-dose cyclophosphamide and bevacuzimab in recurrent, refractory ovarian cancer [27]. Low-dose cyclophosphamide has also been used with low-dose metrotrexate in the treatment of metastatic breast cancer and some of the responses have been demonstrated [28, 29].

An important component of metronomic therapy remains a challenge for researchers - the validation of a surrogate marker of angiogenesis that can be used to monitor treatment activity and verify if a therapy is truly anti-angiogenic. Such a marker is necessary since this new approach to cancer therapy may not result in rapid tumor regression. To date, none of the plasma markers studied such as VEGF, bFGF and TSP-1 have been successfully validated as being able to monitor the activity of anti-angiogenic metronomic chemotherapy. Current evidence suggests that there appears to be much more hope in studying circulating endothelial cells (CECs) and circulating endothelial progenitors (CEPs) as potential surrogate markers. Recently, Bertolini et al. observed a differential effect of
MTD and LDM cyclophosphamide on CEPs: high-dose cyclophosphamide induced a robust immobilization of CEP resulting in drug resistance while LDM cyclophosphamide resulted in a decrease in the number and viability of CEPs and sustained inhibition of tumor growth [16]. A major challenge in using CECs and CEPS, however, is the standardization of analytical methodologies and this is something that must be addressed particularly if multicenter studies will be conducted. Another challenge is the 're-definition' of valid clinical endpoints that should be incorporated into studies of anti-angiogenic therapies. It is becoming increasingly accepted that the classic RECIST criteria may not apply in the evaluation of these therapies. For the time being, as this approach is being tested in early phase clinical trials meaning that patients with late stage disease and high tumor burdens are being evaluated, the ability of a therapy to induce tumor dormancy which can result in stable disease with good quality of life can and should be regarded as a valid clinical endpoint.

The study of LDM or anti-angiogenic chemotherapy has truly opened up a whole new field for researchers and patients alike. New strategies incorporating this therapy being developed and studied include the concurrent use of LDM chemotherapy and MTD chemotherapy which may lead to even higher rates of remission as demonstrated preclinically by Pietras and Hanahan [30] and as is currently investigated by the Children's Oncology Group for metastatic Ewing's sarcoma. Furthermore, pharmaceutical companies are now interested in developing drugs that can be used metronomically in combination with anti-angiogenic agents.

Based on the available evidence, LDM chemotherapy is far from a myth. There clearly is a great deal of promise in this approach, however, the future success of incorporating it into routine practice requires that a consensus be reached on several major issues including: a clear definition of LDM chemotherapy that related to anti-angiogenesis, the identification of appropriate anti-angiogenic agents to be combined with LDM chemotherapy, the definition of the optimum biological doses of these agents, the validation of biomarkers to monitor treatment activity, the confirmation of long-term safety since due to the chronic nature of administration, the selection of a disease subset that is likely to respond to a particular therapy, and the design of clinical trials and incorporation of new clinical endpoints that can truly speak to the effectiveness of these therapies.

\section{References}

1 Shimizu K, Oku N: Cancer anti-angiogenic therapy. Biol Pharm Bull 2004;27:599-605.

2 Hahnfeldt P, Folkman J, Hlatky L: Minimizing long-term tumor burden: the logic for metronomic chemotherapeutic dosing and its antiangiogenic basis. J Theor Biol 2003:220:545-554.
3 Miller KD, Sweeney CJ, Sledge GW, Jr.: Redefining the target: chemotherapeutics as antiangiogenics. J Clin Oncol 2001;19:1195-1206.

4 Bocci G, Nicolaou KC, Kerbel RS: Protracted lowdose effects on human endothelial cell proliferation and survival in vitro reveal a selective antiangiogenic window for various chemotherapeutic drugs. Cancer Res 2002;62:6938-6943.
5 Kamen BA: Metronomic therapy: it makes sense and is patient friendly. J Pediatr Hematol Oncol 2005;27:571-572.

6 Margolin JF, Poplack DG: Acute lymphoblastic leukemia; in Pizzo PA, Poplack DG (eds): Principles and Practice of Pediatric Oncology (ed 3). Philadelphia, Lippincott-Raven, 1997, pp. 409-461. 
7 Rubie H, Coze C, Plantaz D, Munzer C, Defachelles AS, Bergeron C, Thomas C, Chastagner P, Valteau-Couanet D, Michon J, Mosseri V, Hartmann O: Localised and unresectable neuroblastoma in infants: excellent outcome with low-dose primary chemotherapy. $\mathrm{Br}$ J Cancer 2003;89: 1605-1609.

8 Green DM, Breslow NE, Beckwith JB, Finklestein JZ, Grundy P, Thomas PR, Kim T, Shochat S, Haase G, Ritchey M, Kelalis P, D’Angio GJ: Effect of duration of treatment on treatment outcome and cost of treatment for Wilms' tumor: a report from the National Wilms' Tumor Study Group. J Clin Oncol 1998;16:3744-3751.

9 Klement G, Baruchel S, Rak J, Man S, Clark K, Hicklin DJ, Bohlen P, Kerbel RS: Continuous lowdose therapy with vinblastine and VEGF receptor2 antibody induces sustained tumor regression without overt toxicity. J Clin Invest 2000;105: R15-R24.

10 Browder T, Butterfield CE, Kraling BM, Shi B, Marshall B, O'Reilly MS, Folkman J: Antiangiogenic scheduling of chemotherapy improves efficacy against experimental drug-resistant cancer. Cancer Res 2000;60:1878-1886.

11 Soffer SZ, Moore JT, Kim E, Huang J, Yokoi A, Manley C, O'Toole K, Stolar C, Middlesworth W, Yamashiro DJ, Kandel JJ: Combination antiangiogenic therapy: increased efficacy in a murine model of Wilms tumor. J Pediatr Surg 2001;36:1177-1181.

12 Klement G, Huang P, Mayer B, Green SK, Man S, Bohlen P, Hicklin D, Kerbel RS: Differences in therapeutic indexes of combination metronomic chemotherapy and an anti-VEGFR-2 antibody in multidrug-resistant human breast cancer xenografts. Clin Cancer Res 2002;8:221-232.

13 Bello L, Carrabba G, Giussani C, Lucini V, Cerutti F, Scaglione F, Landre J, Pluderi M, Tomei G, Villani R, Carroll RS, Black PM, Bikfalvi A: Low-dose chemotherapy combined with an antiangiogenic drug reduces human glioma growth in vivo. Cancer Res 2001;61:7501-7506.

14 Teicher BA, Sotomayor EA, Huang ZD: Antiangiogenic agents potentiate cytotoxic cancer therapies against primary and metastatic disease. Cancer Res 1992;52:6702-6704.

15 Shaked Y, Bertolini F, Man S, Rogers MS, Cervi D, Foutz T, Rawn K, Voskas D, Dumont DJ, Ben David Y, Lawler J, Henkin J, Huber J, Hicklin DJ, D'Amato RJ, Kerbel RS: Genetic heterogeneity of the vasculogenic phenotype parallels angiogenesis; Implications for cellular surrogate marker analysis of antiangiogenesis. Cancer Cell 2005;7:101-111.

16 Bertolini F, Paul S, Mancuso P, Monestiroli S, Gobbi A, Shaked Y, Kerbel,RS: Maximum tolerable dose and low-dose metronomic chemotherapy have opposite effects on the mobilization and viability of circulating endothelial progenitor cells. Cancer Res 2003:63:4342-4346.

17 Shaked Y, Emmenegger U, Man S, Cervi D, Bertolini F, Ben David Y, and Kerbel RS: The optimal biological dose of metronomic chemotherapy regimens is associated with maximum antiangiogenic activity. Blood 2005.

18 Sterba J, Valik D, Mudry P, Kepak T, Pavelka Z, Bajciova V, Zitterbart K, Kadlecova V, Mazanek P: Combined biodifferentiating and antiangiogenic oral metronomic therapy is feasible and effective in relapsed solid tumors in children: single-center pilot study. Onkologie 2006;29: DOI: 10.1159/ 000093474 .
19 Kieran MW, Turner CD, Rubin JB, Chi SN, Zimmerman MA, Chordas C, Klement G, Laforme A, Gordon A, Thomas A, Neuberg D, Browder T, Folkman J: A feasibility trial of antiangiogenic (metronomic) chemotherapy in pediatric patients with recurrent or progressive cancer. J Pediatr Hematol Oncol 2005;27:573-581.

20 Baruchel S, Diezi M, Hargrave D, Stempak D, Gammon J, Moghrabi A, Coppes M, Fernandez CV, Bouffet E: Safety and pharmacokinetic of temozolomide using a dose-escalation, metronomic schedule in recurrent pediatric brain tumors. Eur J Cancer 2006, in press.

21 Stempak D, Gammon J, Koren G, Baruchel S: Does metronomic chemotherapy combined with celecoxib provide anti-angiogenic therapy for pediatric recurrent solid tumors? New Directions in Angiogenesis Research - an AACR Special Conference in Cancer Research 2003 (Abstr).

22 Maraveyas A, Lam T, Hetherington JW, Greenman J: Can a rational design for metronomic chemotherapy dosing be devised? Br J Cancer 2005;92: 1588-1590.

23 Kerbel RS, Kamen BA: The anti-angiogenic basis of metronomic chemotherapy. Nat Rev Cancer 2004:4:423-436.

24 Stempak D, Seely D, Baruchel S: Metronomic Chemotherapy: applications in pediatric oncology. Cancer Invest 2006, in press.

25 Buckstein R, Crump M, Shaked Y, Nayar R, Foden C, Turner D, Foden C, Man S, Baruchel S, Stempak D, Bertolini F, Kerbel RS: High dose celecoxib and metronomic 'low dose' cyclophosphamide is effective and safe therapy in patients with relapsed and refractory aggressive histology non-Hodgkin's lymphoma. Clin Cancer Res 2006, in press.

26 Young SD, Whissell M, Noble JC, Cano PO, Lopez PG, Germond CJ: Phase II clinical trial results involving treatment with low-dose daily oral cyclophosphamide, weekly vinblastine, and rofecoxib in patients with advanced solid tumors. Clin Cancer Res 2006;12:3092-3098.

27 Garcia AA, Oza AM, Hirte H, Fleming G, TsaoWei D, Roman L, Swenson S, Gandara D, Scudder S, Morgan R: Interim report of a phase II clinical trial of bevacizumab (Bev) and low dose metronomic oral cyclophosphamide (mCTX) in recurrent ovarian (OC) and primary peritoneal carcinoma: A California Cancer Consortium Trial. J Clin Oncol 2005;23(16S), 5000 (Abstr).

28 Colleoni M, Rocca A, Sandri MT, Zorzino L, Masci G, Nole F, Peruzzotti G, Robertson C, Orlando L, Cinieri S, de BF, Viale G, Goldhirsch A: Low-dose oral methotrexate and cyclophosphamide in metastatic breast cancer: antitumor activity and correlation with vascular endothelial growth factor levels. Ann Oncol 2002;13:73-80.

29 Bocci G, Tuccori M, Emmenegger U, Liguori V, Falcone A, Kerbel RS, Del Tacca M: Cyclophosphamide-methotrexate 'metronomic' chemotherapy for the palliative treatment of metastatic breast cancer. A comparative pharmacoeconomic evaluation. Ann Oncol 2005;16:1243-1252.

30 Pietras K, Hanahan D: A multitargeted metronomic, and maximum-tolerated dose 'chemo-switch' regimen is antiangiogenic, producing objective responses and survival benefit in a mouse model of cancer. J Clin Oncol 2005;23:939-952. 